\title{
O CANTEIRO CENTRAL DA AVENIDA MINAS GERAIS: UMA ANÁLISE A PARTIR DAS DEMANDAS DEMOGRÁFICAS DE USUÁRIOS DO ENTORNO
}

\author{
Lucas Alves Pereira \\ Universidade Federal de Uberlândia, Instituto de Geografia \\ Pós-Graduação em Geografia, Uberlândia, MG, Brasil \\ lapereira.geo@gmail.com \\ Carlos Roberto Loboda \\ Universidade Federal de Uberlândia, Instituto de Ciências Humanas do Pontal \\ Pós-Graduação em Geografia do Pontal, Ituiutaba, MG, Brasil \\ crloboda@gmail.com
}

\begin{abstract}
RESUMO
A proposta aqui trabalhada versa sobre a relação do canteiro central da Avenida Minas Gerais em Ituiutaba (MG) e seu entorno, tendo como objetivo identificar a partir de faixas etárias os maiores contingentes populacionais do entorno, relacionando com os lugares não abarcados por um sistema de áreas verdes urbana. O percurso teóricometodológico consistiu em uma abordagem a partir da produção do espaço urbano, por meio da qual o homem em certa medida organiza a morfologia urbana ao longo do tempo, reestruturando-a por meio da diferenciação dos lugares, chegando ao sistema de espaços livres e, por conseguinte as áreas verdes. Dessa forma, trabalhamos com as áreas verdes urbanas que são elementos importantes, constituintes e estruturadores não somente do sistema de espaços livres, mas do próprio espaço urbano. A relação dos dados demográficos do entorno e do canteiro da avenida Minas Gerais delineou nossa base analítica, sendo possível verificarmos a área como importante espaço público enquanto potencialidade e possibilidade. Dessa forma, pudemos por meio do processo de pesquisa caracterizar o entorno e apontar três localizações possíveis para intervenções, se beneficiando de sua posição para realizar a implantação de equipamentos e proporcionar melhor uso através de incentivos e instrumentos urbanísticos.
\end{abstract}

Palavras-chave: Produção do espaço urbano. Espaços livres. Áreas verdes. Canteiro central.

\section{THE CENTRAL RESERVATION OF AVENIDA MINAS GERAIS: AN ANALYSIS FROM DEMOGRAPHIC DEMANDS OF USERS IN THE ENVIRONMENT}

\begin{abstract}
The proposal worked on here deals with the relationship between the central reservatoion of Avenida Minas Gerais in Ituiutaba (MG) and its surroundings, with the objective of identifying from age groups the largest population contingents in the surroundings, relating to places not covered by a system of urban green areas. The theoretical-methodological path consisted of an approach based on the production of urban space, through which man to some extent organizes urban morphology over time, restructuring it through the differentiation of places, reaching the system of spaces free and therefore green areas. In this way, we work with urban green areas that are important elements, constituents and structuring not only of the free space system, but of the urban space itself. The relationship of the demographic data of the surrounding area and of the Minas Gerais avenue reservation delineated our analytical base, being possible to verify the area as an important public space as potentiality and possibility, in this way, we were able through the research process to characterize the surroundings and to point out three locations possible for interventions, benefiting from its position to carry out the implementation of equipment and provide better use through incentives and urban instruments.
\end{abstract}

Keywords: Production of urban space. Free spaces. Green areas. Central reservation. 


\section{INTRODUÇÃO}

A cidade apresenta uma paisagem característica a partir dos processos sociais e o modo de produção estabelecido em cada momento da história, sendo estes realizados a princípio em uma base natural. Consequentemente, o espaço geográfico se configura de maneira específica ao longo do tempo, indo de uma organização à produção. A relação campo e cidade se transformou e uma urbana se constituiu. A cidade como lócus da produção e reprodução passa a receber cada vez mais contingentes humanos e, por conseguinte ocorre o agravamento e desequilíbrio na relação sociedade e natureza e entre a própria sociedade incialmente fomentando pelo processo de industrialização. Em se tratando das formas na paisagem, as contradições entre público e privado, áreas edificadas e áreas livres de edificação, de uso controlado e de uso livre se apresentam ao longo de uma morfologia que manifesta na contemporaneidade características marcantes do capitalismo pós-industrial. Neste jogo constante entre capital e a sociedade, os espaços de sociabilidade e atenuação da relação agressiva entre homem e meio acabam por serem considerados "inúteis", pois pouco contribuem para a reprodução capitalista. Assim se apresentam cada vez menos disponíveis em quantidade e/ou qualidade.

Procurando contribuir com as discussões sobre o tema, o presente trabalho versa sobre o canteiro central da Avenida Minas Gerais, que constitui para a cidade de Ituiutaba (localizada no Estado de Minas Gerais) um potencial de uso social, ecológico e de lazer, tendo em vista sua extensão e localização.

A área em questão conta com usos específicos da população, mas que pouco se aproveitam de suas potencialidades. Utiliza-se deste espaço para recreação de crianças que se apropriam dos canteiros gramados, realizando brincadeiras das mais diversas; por adultos que realizam treinos esportivos ou para passarem o tempo livre, significando que usuários já procuram o canteiro da Avenida Minas Gerais.

Vemos então a necessidade de equipar melhor determinados pontos do canteiro para receber os usos, ainda que para dar segurança aos mesmos. Também é possível observar que determinadas áreas do canteiro permitem intervenções em nível de estabelecer novos usos, visando aproveitar toda a potencialidade do canteiro, tendo em vista estarem fora de abrangência de outras áreas verdes urbanas da cidade, gerando assim possibilidades, tanto de incentivar e melhorar as formas de uso existentes ou fundamentar novos usos.

Portanto, considerando o canteiro como uma área verde urbana com usos incipientes, relacionando-a com as demais áreas da cidade, considerando também as características demográficas do entorno, propomos como objetivo deste trabalho identificar os maiores contingentes populacionais do entorno a partir de cada faixa etária. De maneira complementar o objetivo principal se desdobra em uma segunda etapa, visando relacionar os contingentes aos lugares não abarcados por nenhuma área verde urbana.

Desta maneira, a proposta aqui trabalhada se justifica devido o interesse em compreender as características do entorno da Avenida Minas Gerais, no contexto de área verde urbana para a cidade de Ituiutaba. Contribuindo assim, para o preenchimento da lacuna de estudos locais. Ainda, ressaltamos que tal proposição está ancorada na valoração de um importante espaço público na cidade de Ituiutaba.

\section{Área de estudo}

Os canteiros da Avenida Minas Gerais correspondem em área aproximadamente $125.000 \mathrm{~m}^{2}$, sendo 5 $\mathrm{km}$ de comprimento e cortada por 30 interseções (ruas). O canteiro está disposto na malha urbana de Ituiutaba no sentido de sudoeste - nordeste. Considerado a metodologia adotada, a área de abrangência abarca no total 15 bairros (Figura 1). No entanto, no presente trabalho foram considerados apenas 14, tendo em vista que o bairro Gerson Baduy apresenta pouca população residente, ainda não contando no último censo realizado em 2010 devido a sua recente incorporação. Na área de abrangência são encontrados espaços livres de tipologia pública e privada, bem como a presença de 
áreas verdes urbanas na ordem de praças, clubes, um centro turístico com quadras poliesportivas, mas ainda carente de equipamentos e usos.

Figura 1 - Bairros do entorno da Avenida Minas Gerais.

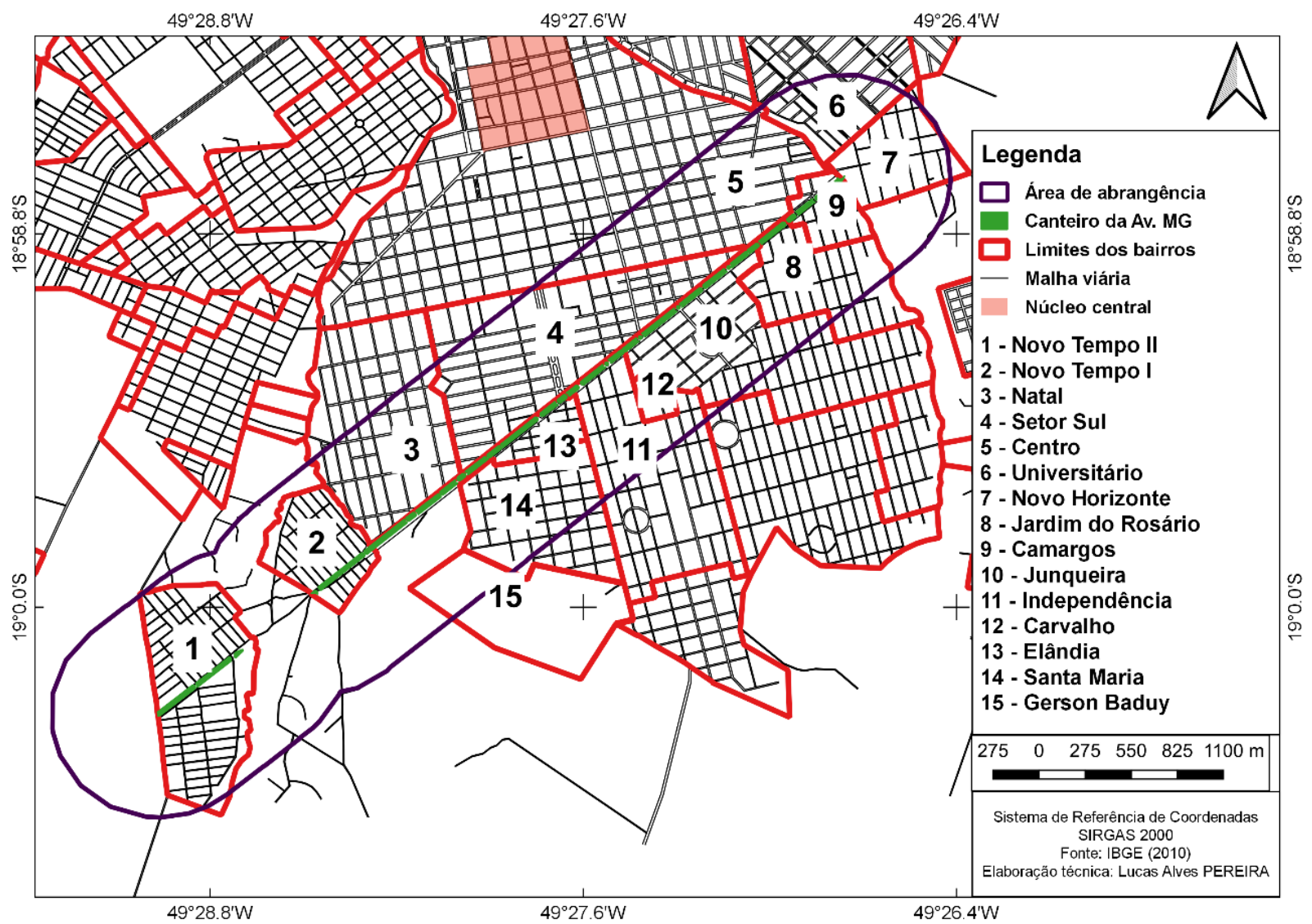

Fonte - IBGE, 2010; Organização - Lucas Alves Pereira, 2017.

De acordo com o Código de Trânsito Brasileiro (CTB), a avenida poderia ser considerada como via arterial, como "aquela caracterizada por interseções em nível, geralmente controlada por semáforo, com acessibilidade aos lotes lindeiros e às vias secundárias e locais, possibilitando o trânsito entre as regiões da cidade", com velocidade máxima de $60 \mathrm{~km} / \mathrm{h}$. No entanto é classificada como via coletora sendo "aquela destinada a coletar e distribuir o trânsito que tenha necessidade de entrar ou sair das vias de trânsito rápido ou arteriais, possibilitando o trânsito dentro das regiões da cidade", com velocidade máxima de $40 \mathrm{~km} / \mathrm{h}$.

A área de abrangência é essencialmente residencial, com a presença de pequenas empresas comerciais, inexpressivas do ponto de vista a atender as demandas da população dos bairros neste setor da cidade, tendo em vista a forte monocentrização em Ituiutaba. Porém, destaca-se por sua influência o supermercado atacadista Mart Minas, localizado entre os bairros Natal, Santa Maria e Gerson Baduy I, este último não identificado no mapa devido a baixa ocupação e a ausência no censo de 2010. Destaca-se também, o Centro Turístico Camilo Chaves Neto, localizado entre os bairros Novo Tempo II e Novo Tempo I.

Sobre a consolidação dos bairros, estes ocorreram em períodos distintos, tendo iniciado pelo centro em direção à periferia da cidade de Ituiutaba, conforme especificado no quadro 1 . 
Quadro 1 - Periodização da formação dos bairros.

\begin{tabular}{|c|c|}
\hline Década & Bairros \\
\hline 1930 & Centro. \\
\hline 1940 & $\begin{array}{c}\text { Natal, Santa Maria, Independência, Junqueira e } \\
\text { Novo Horizonte. }\end{array}$ \\
\hline 1950 & $\begin{array}{c}\text { Elândia, Camargos, Jardim do Rosário, Carvalho } \\
\text { e Setor Norte }\end{array}$ \\
\hline 1980 & Universitário. \\
\hline 1990 & Novo Tempo I e Novo Tempo II. \\
\hline 2010 & Gerson Baduy I. \\
\hline
\end{tabular}

Fonte - Oliveira (2013); Organização: : Lucas Alves Pereira (2016).

Portanto, devido à consolidação dos bairros em diferentes períodos, a Avenida Minas Gerais recebeu diversas obras de infraestrutura ao longo das últimas décadas, a depender do crescimento da cidade. Ainda hoje, são implantadas obras para melhoria do fluxo de veículos a partir da pavimentação do trecho que liga o bairro Novo Tempo II ao restante da cidade, pela avenida Minas Gerais.

\section{PERCURSO METODOLÓGICO}

Visando atender ao objetivo proposto, a princípio o esforço foi selecionar material bibliográfico acerca do tema. A escolha se deu a partir das palavras-chave: produção do espaço urbano, sistema de espaços livres e áreas verdes urbanas. Para o caminho teórico-metodológico, buscamos uma ordem lógica que consiste em iniciar a abordagem a partir da produção do espaço urbano onde o homem em certa medida organiza a morfologia urbana ao longo do tempo, reestruturando-a por meio da diferenciação dos lugares, portanto, o sistema de espaços livres tem ligação direta com esta morfologia. As áreas verdes urbanas junto às outras formas urbanas vão compor então este sistema de espaços livres. Entretanto cabe a diferenciação entre ambos, pois apresentam distintas funções e usos, sendo assim, devido às nuances sutis, carecendo de um momento especifico, maior aprofundamento da conceituação será realizado adiante.

Tendo organizado a forma de abordagem e o material teórico, o conteúdo técnico do trabalho foi selecionado a partir de base de dados do Instituto Brasileiro de Geografia e Estatística (IBGE). A organização dos dados foi realizada com base no interesse em quantificar crianças ( 0 a 11 anos), adolescentes (12 a 18 anos) e idosos (mais de 60 anos) no raio de abrangência estabelecido a partir do canteiro da Avenida Minas Gerais, com prioridade para crianças e idoso, entendendo que estes não são os únicos usuários de espaços livres e áreas verdes, mas são os que possuem maior capacidade de apropriação destes espaços em decorrência de seu tempo livre, bem como pela socialização, que é de grande importância a estas faixas etárias. Segundo Nucci (2008, p. 37), a utilização dos espaços livres independe da classe social e idade, pois, o desfrute do momento de folga ocorre da melhor maneira que convém a cada indivíduo, criando uma demanda de espaços livres que possibilitem o cumprimento da função recreativa devido ao aumento da expectativa de vida dos idosos e o tempo disponível das crianças que necessitam de se ocupar com lazer, atividades físicas e contato social, melhorando sua qualidade de vida.

A delimitação das idades se deu com base na lei que dispõe sobre o Estatuto da Criança e do

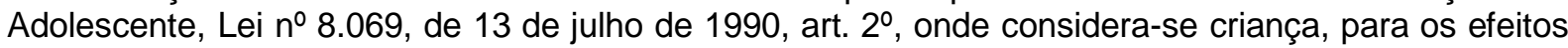
desta Lei, a pessoa até doze anos de idade incompletos, e adolescente aquela entre doze e dezoito 
anos de idade. Também o Estatuto do Idoso, por meio da lei oㅜ 10.741, de $1^{\circ}$ de outubro de 2003, art. $1^{\circ}$, que regulamenta os direitos assegurados às pessoas com idade igual ou superior a sessenta anos.

Neste trabalho foi preciso estabelecer uma abrangência para a área verde urbana em estudo (o canteiro da avenida Minas Gerais) utilizando-se como embasamento estudos de Di Fidio (1985, apud NUCCI, 2008, p.34), que aponta que "um grande peso é a distância entre o usuário e o espaço livre, [...] em distâncias maiores do que 10 a 15 min, a pé a utilização decai". Considerando a velocidade de caminhada (NOVAES; MIRANDA; DOURADO, 2011) de idosos com base para uma acessibilidade universal, foi atribuído um raio de abrangência de 600 metros, observando a possibilidade de percorrer esta distância em 10 a 15 min.

Com base na abrangência foi realizado também o levantamento de praças e outras possíveis áreas verdes urbanas, de modo evidenciar a importância de determinadas porções do canteiro.

É importante salientar que pensar o canteiro da Avenida Minas Gerais enquanto área verde urbana, não significa que tenha se estabelecido uma finitude do que está posto em infraestrutura local, pensamos esta área a partir do uso incipiente e da potencialidade que se apresenta.

\title{
PRODUÇÃO DO ESPAÇO URBANO E ÁREAS VERDES
}

Determinado pelas contradições, o espaço urbano cresce sendo orientado pelos interesses do poder e capital para fazê-lo, gerando os conflitos a partir da posse da propriedade privada do solo e da moradia, com a distinção bem definida entre público e privado, sendo produzido de forma homogênea e baseado no valor de troca. Como está baseada no modo de produção capitalista, "A produção e apropriação do espaço urbano não só reflete as desigualdades e as contradições sociais, como também as reafirma e reproduz" (MARICATO, 2002, p. 170), sendo desta forma, notório que o conflito se instale no processo e acabe por apresentar uma divisão social e espacial do trabalho, por conseguinte orienta a energia para o desenvolvimento de determinadas áreas em detrimento de outras.

\begin{abstract}
"A terra urbana e a habitação são objetos de interesse generalizado, envolvendo agentes sociais com ou sem capital, formal ou informalmente organizados. Estabelece-se uma tensão, ora mais, ora menos intensa, porém permanente, em torno da terra urbana e da habitação. Se isso não constitui a contradição básica, transformase, contudo, em problema para uma enorme parcela da população" (CORREA, 2014, p. 47).
\end{abstract}

Lefebvre (2001, p. 86) ajuda a compreensão, tratando que o espaço urbano não se define apenas por uma morfologia material (prático-sensível), nem como algo sem ela. Não constitui essência atemporal, nem um sistema desligado ou hierarquizado de outros sistemas. É, pois, uma forma mental e social, a forma da simultaneidade, do encontro, surgindo à qualidade que nasce das quantidades de espaços, objetos e produtos. É constituído por diferenças, ou seja, baseado na heterogeneidade em grande escala, ainda que orientado pela produção capitalista tende a uma homogeneização.

A produção do espaço repousa para Henri Lefebvre 2000, na ideia de que

o modo de produção organiza e produz, ao mesmo tempo que certas relações sociais, também o seu espaço (e seu tempo). É assim que ele se realiza, posto que o modo de produção projeta sobre o terreno estas relações, sem, todavia, deixar de considerar o que constitui sobre ele. Certamente, não existiria uma correspondência exata, assinala antes entre relações sociais e as relações espaciais (ou espaço-temporais) (LEFEBVRE, 1981, p. vii apud CARLOS, 2014,p. 57).

A sociedade nova se apropria do espaço preexistente, modelando anteriormente; a organização anterior se desintegra e o modo de produção integra os resultados (CARLOS, 2014, p. 57). Portanto, deve-se considerar que,

"A produção do espaço, seja o da rede urbana, seja do intraurbano, não é o resultado da "mão invisível do mercado", nem de um Estado hegeliano, visto como entidade supraorgânica, ou de um capital abstrato que emerge de fora das relações sociais. É consequência da ação de agentes sociais concretos, históricos, dotados de interesses, estratégias e práticas espaciais próprias, portadores de contradições e geradores de conflitos entre eles mesmos e com outros segmentos da sociedade" (CORREA, 2014, p. 43). 
Fazem parte dos elementos do espaço segundo Santos (2014, p. 16): os homens; as firmas; as instituições; o meio ecológico; e as infraestruturas. Estes se interagem para a produção do espaço pelos atores envolvidos, sendo segundo Grafmeyer (1995, p. 117-118, apud VASCONCELOS, 2014, p. 75) que a noção de ator seria utilizada para os casos em que a pessoa está envolvida em relação de papéis com um ou vários protagonistas, utilizando o termo agente para os outros casos. Os atores estão em vários lugares e possuidores de ação (SANTOS, 2014).

A urbanização enquanto processo formador do espaço urbano se assentando na noção da propriedade e se desenrola pelas ações de seus atores e agentes produtores, que realizam ações que transformam os processos sociais na forma de um ambiente construído. Segundo Correa (1989, p. 25; 2011, p. 122; 2014 , p. 44) os agentes e também atores se apresentam na forma do Estado, os proprietários dos meios de produção, os proprietários fundiários, os promotores imobiliários, ligados ou não ao grande capital e os grupos sociais excluídos. Corrobora sobre a influência dos agentes de produção, Salgueiro (2001, p.69) apud Vasconcelos (2014, p.77), destacando na produção de ambientes urbanos "(i) o Estado como um ator privilegiado; e outros agentes relevantes seriam: (ii) os proprietários do solo; (iii) os promotores; (iv) os construtores; (v) os financiadores; (vi) os mediadores; e (vii) os utilizadores. Ela ainda menciona três tipos de promotores-construtores: o Estado e as autarquias; as empresas imobiliárias e os pequenos e médios promotores".

Por fim, se faz necessário uma síntese das características do que se entende por espaço urbano socialmente produzido, que diretamente modela a cidade na forma e ideologia. Quanto à sua produção, segundo Correa (2011), pode ser definido a partir de seis perspectivas: 1) como um espaço fragmentado, caracterizado pela justaposição de diferentes paisagens e usos da terra; 2) através da articulação, o espaço urbano ganha unidade, originando um conjunto articulado cujo foco de articulação tem sido o núcleo central da cidade que, entre outras funções, realiza a gestão de atividades. A articulação se manifesta empiricamente através dos fluxos e veículos e de pessoas. Também se manifesta a partir do capitalismo, através das relações envolvendo a circulação de decisões e investimentos de capital, mais-valia, salários, juros, renda, envolvendo ainda a prática do poder e da ideologia em sua dimensão espacial; 3) ser reflexo da sociedade, o espaço urbano pode ser o reflexo de uma sequência de formas espaciais que coexistem lado a lado, cada uma sendo originária de uma dado momento; 4) condicionante social, se realizando através do papel que as obras fixadas pelo homem, as formas espaciais, desempenham na produção das condições de produção e das relações de produção; 5) lugar onde os diferentes grupos sociais vivem e se reproduzem. Isso envolve o cotidiano e o futuro, crenças, valores, mitos, utopias e conflitos criados no bojo da sociedade de classes e em parte projetados nas formas espaciais - momentos, lugares de lazer, etc. Formas espaciais em relação às quais o homem desenvolve sentimentos, cria laços de afeição ou delas desgosta, atribuiIhes a propriedade de proporcionar felicidade ou status, ou associar-se a dor ou pobreza. O espaço urbano torna-se assim, um campo simbólico que tem dimensões e significados variáveis segundo as diferentes classes e grupos etário, étnico, etc.; 6) cenário e objeto das lutas sociais, pois estas visam, afinal de contas, o direito à cidade, à cidadania pela e igual para todos, o espaço urbano converte-se, assim, em campo de lutas.

Estabelecido um marco teórico em torno da produção do espaço urbano, entendendo que nele se manifestam as distintas formas dentro de uma morfologia historicamente construída, a compreensão da configuração territorial e a relação entre estas formas podem ser melhor compreendidas, e dentro destas, as Áreas Verdes, que podem se apresentar enquanto privadas ou públicas, esta última melhor apreciada neste trabalho.

As Áreas Verdes Urbanas compõem o Sistema de Áreas Livres, sendo de grande importância para a vida nas cidades, pois seus benefícios são relacionados ao bem estar humano, devido ao cumprimento de suas funções.

\begin{abstract}
"As áreas verdes urbanas são de extrema importância para a qualidade de vida urbana. Elas agem simultaneamente sobre o lado físico e mental do Homem, absorvendo ruídos, atenuando o calor do sol; no plano psicológico, atenua o sentimento de opressão do Homem com relação às grandes edificações; constitui-se em eficaz filtro de partículas sólidas em suspensão no ar, contribui para a formação e o aprimoramento do senso estético, entre tantos outros benefícios" (LOBODA e DE ANGELIS, 2005, p. 134).
\end{abstract}

As funções podem ser estabelecidas a partir da seguinte figura esquemática (Figura 2): 
Figura 2 - Funções das Áreas Verdes Urbanas.

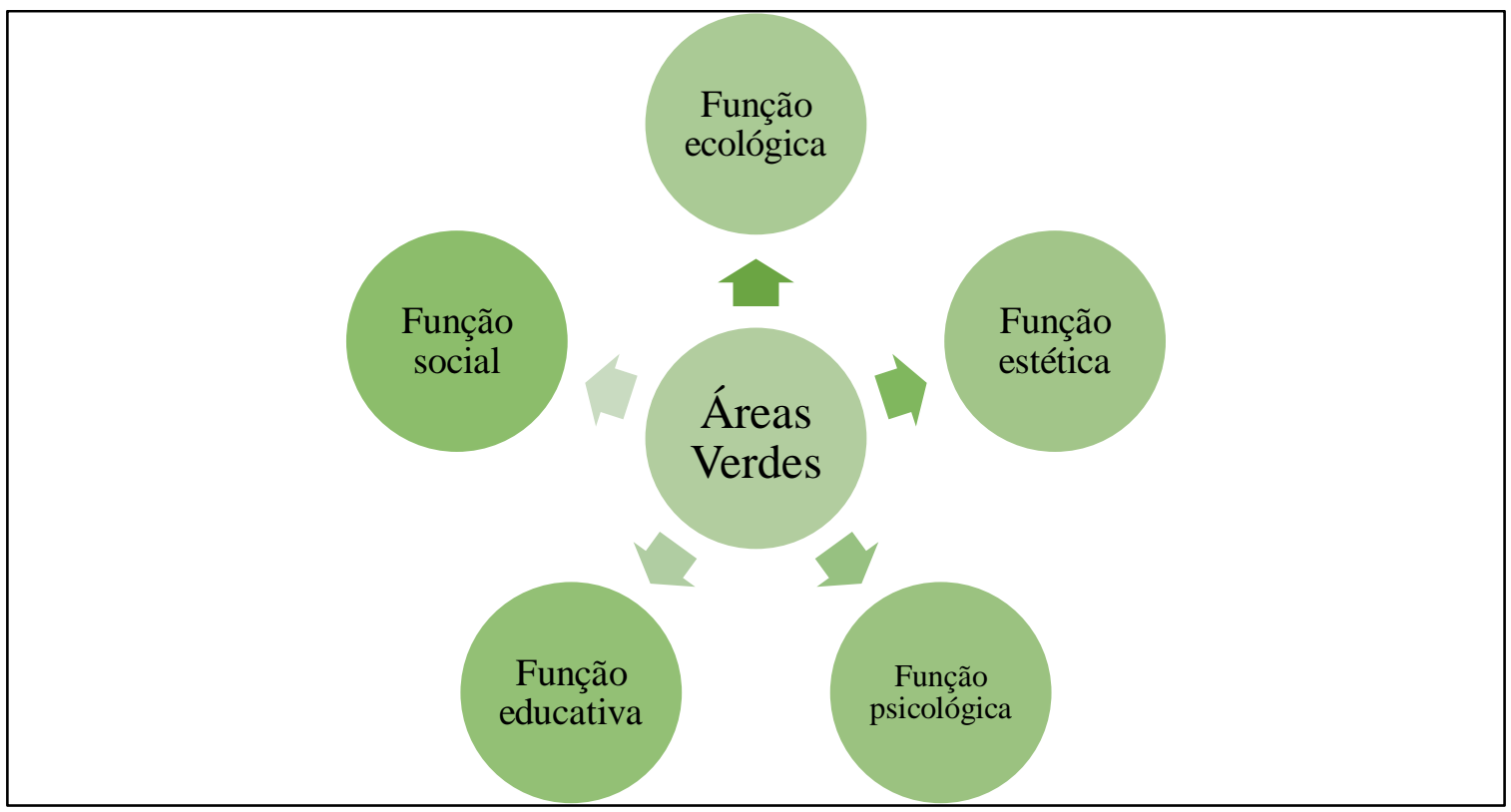

Fonte - BARGOS e MATIAS, 2011; Adaptação: : Lucas Alves Pereira (2016).

Seguindo as funções esquematizadas, Bargos e Matias (2011, p.181) especificam que:

$>$ Função Ecológica: ganho qualitativo nos elementos clima local, qualidade do ar, água e solo e fauna.

> Função Social: possibilidade de lazer que essas áreas oferecem a população. Com relação a este aspecto, deve-se considerar a necessidade de hierarquização.

> Função Educativa: ambiente para o desenvolvimento de atividades educativas, extraclasse e de programas de educação ambiental.

- Função Psicológica: recreação e lazer ao ar livre trazendo ganhos qualitativos.

> Função Estética: diversificação da paisagem construída e embelezamento da cidade. A vegetação se mostra muito importante nessa função.

Nem sempre a área verde urbana em questão irá contemplar efetivamente todas as funções, mas espera-se que, em certa medida, atinja nível suficiente de características para que Ihe seja atribuída sua conotação. Como exemplo, nem sempre a função social é cumprida devido à maneira que está disposta, bem como seu conteúdo inviabilizar o acesso de muitas pessoas. De outra maneira, a função ecológica pode ficar comprometida por conta das dimensões ou porte arbustivo de uma área verde urbana. Ademais, segundo Serpa (2014, p. 87), a "distância e acessibilidade, dois conceitos geográficos fundamentais, acabam colocando em xeque a noção mesma do parque urbano como espaço público", o autor segue dizendo ainda que "integrar os bairros no tecido urbano, melhorar a qualidade de vida, resolver os conflitos sociais através de intervenções espaciais, eis os novos papéis atribuídos aos parques públicos no contexto urbano" (SERPA, 2014, p.84).

Cabe ao planejamento fazer bom uso dos espaços urbanos, utilizando-se das Áreas Verdes em locais estratégicos, bem como em lugares não apropriados pela lógica do capital imobiliário, o que significa que ao integrarem o Sistema de Espaços Livres, gera uma distribuição adequada sobre a malha urbana, pois

"Como indicador de qualidade ambiental as áreas vedes precisam ser consideradas ainda conforme sua distribuição e dimensão espacial para que o planejamento urbano e ambiental supra as necessidades da sociedade e não apenas seja conduzido à valorização e preservação da vegetação no meio urbano por uma questão meramente preservacionista" (BARGOS e MATIAS, 2011, p. 181). 
Neste momento, é preciso diferenciar (Quadro 2) como foi caracterizado por diferentes autores o Espaço Livre, também as Áreas Verdes Urbanas, levando em consideração as dimensões, composição vegetal e continuidade.

Quadro 2 - Categorias e conceitos de Áreas Verdes Urbanas.

\begin{tabular}{|c|c|}
\hline Categoria & Conceito \\
\hline Área verde & $\begin{array}{l}\text { "Onde há o predomínio de vegetação arbórea; engloba as praças, os jardins } \\
\text { públicos e os parques urbanos. Os canteiros centrais e trevos de vias públicas, } \\
\text { que tem apenas funções estéticas e ecológicas, devem, também, conceituar-se } \\
\text { como área verde. Entretanto, as árvores que acompanham o leito das vias } \\
\text { públicas, não devem ser consideradas como tal. Como todo Espaço Livre, as } \\
\text { Áreas Verdes também devem ser hierarquizadas, segundo sua tipologia } \\
\text { (privadas, potencialmente coletivas e públicas)" (LIMA et. al., 1994, p. 548) }\end{array}$ \\
\hline Parque Urbano & $\begin{array}{l}\text { "É uma área verde, com função ecológica, estética e de lazer, entretanto com } \\
\text { uma extensão maior que as chamadas Praças e Jardins Públicos" (LIMA et. al., } \\
\text { 1994, p. 548). }\end{array}$ \\
\hline Praça & $\begin{array}{l}\text { “Como área verde, tem a função principal de lazer. Uma praça, inclusive, pode } \\
\text { não ser uma área verde, quando não tem vegetação e é imperializada; no caso } \\
\text { de ter vegetação é considerada Jardim” (LIMA et. al., 1994, p. 548). }\end{array}$ \\
\hline Arborização Urbana & $\begin{array}{l}\text { "Elementos vegetais de porte arbóreo situados na cidade, como as árvores. } \\
\text { Neste termo estão incluídas as árvores de acompanhamento viário" (LIMA et. } \\
\text { al, 1994, p. 548). }\end{array}$ \\
\hline $\begin{array}{l}\text { Zonas Verdes, } \\
\text { espaços verdes, } \\
\text { áreas verdes, e } \\
\text { equipamento verde }\end{array}$ & $\begin{array}{l}\text { "Qualquer espaço livre no qual predominam as áreas plantadas de vegetação, } \\
\text { correspondendo, em geral, o que se conhece como parques, jardins ou praças" } \\
\text { (LLARDENT, 1982, p } 151 \text { apud LOBODA e De Angelis, 2005, 132). }\end{array}$ \\
\hline
\end{tabular}

Fonte - Lima et. al; Lardenent (1982, apud LOBODA e DE ANGELIS, 2005). Organização: Autor, 2017.

É importante relembrar que mesmo com a quantidade de estudos sobre o tema, o termo área verde urbana por vezes se confunde com espaço livre, até por possuírem essências semelhantes, mas fisicamente distintas. Deste modo, o esforço de compreensão conceitual é cabível para o adensamento do arcabouço teórico já estabelecido sobre Áreas Verdes Urbanas e o Sistema de Espaços Livres, pois, as Áreas Verdes sendo instituídas na cidade de maneira correta, ou seja, via planejamento, ou mesmo a criação ou reconhecimento de parques e praças é fundamental para o bem-estar humano na urbe. Portanto, como é indicado por Serpa (2014, p. 84), o parque urbano na contemporaneidade representa o lugar da sociabilidade. "Ir a um parque é um ato de liberdade. O 'verde' e a 'apropriação da natureza' tornaram-se direitos reivindicados por todos os cidadãos e objeto de preocupação dos gestores das cidades ao redor do mundo". Elucidando também que que "esses espaços de natureza cada vez mais rara representam o antídoto para os ritmos urbanos, o stress e a poluição.

\section{ANÁLISE DO ENTORNO DA AVENIDA MINAS GERAIS}

A densidade populacional nas cidades é de difícil ponderação enquanto a um índice ideal. Faz parte desta complexa relação o barateamento de infraestruturas por indivíduo, no caso de uma densidade maior; sabe-se também que quanto maior a densidade demográfica maiores são alguns problemas urbanos, como fluxo demasiado de veículos, alta geração de resíduos e poluentes numa mesma área, risco de disseminação de doenças, fornecimento de água e energia. Altas concentrações de pessoas demandam maiores ofertas de serviços públicos e privados, ou seja, a partir do interesse do trabalho aqui desenvolvido, maiores quantidades de Espaços Livres e Áreas Verdes.

Entende-se que a densidade demográfica está intimamente relacionada à renda, pois como nos apresenta Santos (2012, p.49), as características da população urbana, por sua vez a densidade demográfica, ajudam de certo modo a entender a estrutura econômica. Portanto, a compreensão da

$\begin{array}{lllll}\text { Caminhos de Geografia } \quad \text { Uberlândia-MG } & \text { v. 21, n. } 76 \quad \text { Ago/2020 } & \text { p. 28-41 Página } 35\end{array}$


estrutura demográfica e econômica pode orientar localizações onde espaços de recreação e lazer público é mais exigido ou carente.

Como trabalhamos com faixas etárias especificas, será utilizado aqui a quantidade de habitantes em detrimento da densidade. Entendemos que a densidade seria melhor utilizada caso toda a população do entorno fosse abarcada.

Partido da quantidade de praças, enquanto área verde urbana nota-se que a distribuição destas não se faz de forma tão precária, no entanto, parte significativa que compreende o bairro Santa Maria e Independência, não dispõem sequer uma única área verde urbana, o que pode ser considerado como uma "grave situação" de "descompromisso" de gestão pública se considerarmos a presença de uma praça nos mapas oficiais, mas que a partir do que foi observado em campo, não contempla minimamente as funções de uma praça.

Para uma melhor didática na apresentação dos resultados trataremos do canteiro da avenida em três segmentos: 1) sudoeste; 2) central; e 3) nordeste. Outro aspecto a ser apontando, no que tange a semiótica, é a utilização da cor lilás em referência às áreas verdes por conta da melhor apresentação da cor verde para o canteiro da Avenida Minas Gerais.

A porção sudoeste tem como característica significativo vazio urbano representado por áreas de reserva da expansão imobiliária, localizadas ao sul da porção, mas que ao mesmo tempo apresenta concentração significativa de crianças tendo como base a população de 0 a 11 anos (Figura 3), se mostrando mediana no bairro Novo Tempo II, mas apresentando alto número no bairro Novo Tempo I.

Enquanto na porção central, se considerado o lado norte, é praticamente toda a área abrangida por áreas verdes urbanas. De outra forma, o lado sul que é abarcado pela abrangência de apenas uma área verde urbana, mas apresentando grande população de crianças (tendo em vista a cidade de Ituiutaba), sobretudo no bairro Santa Maria, sendo assim, demonstra a urgência de intervenção no sentido de prover a instituição de uma área verde urbana dotada de equipamentos que permitam o cumprimento de suas funções.

Figura 3 - Número de crianças por setor censitário (0 a 11 anos).

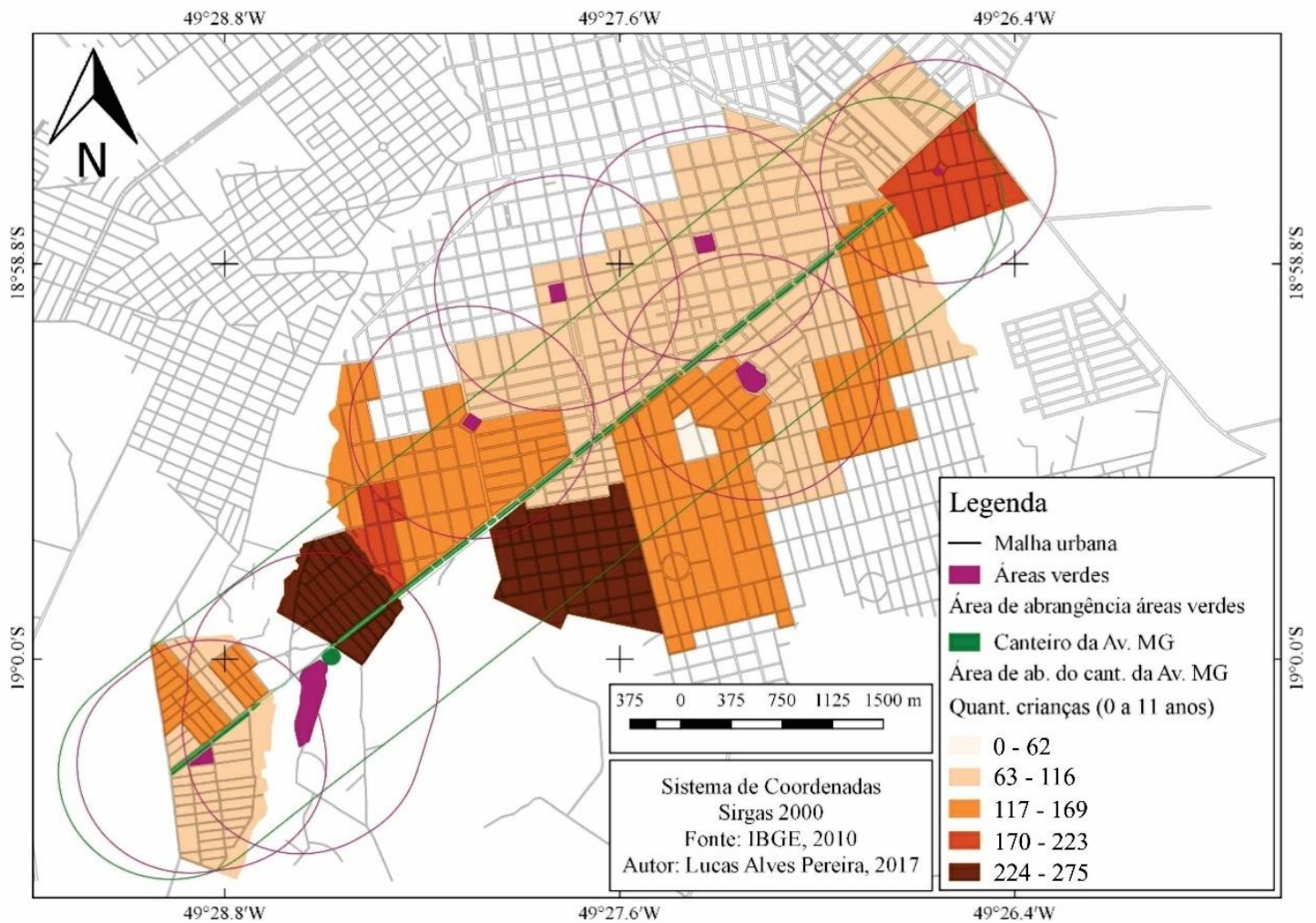

Fonte - IBGE, 2010; Organização: : Lucas Alves Pereira, 2017. 
Chegando à porção nordeste, a população de crianças é mediana em comparação aos demais setores. Este segmento, é quase todo abarcado por abrangência de áreas verdes urbanas, salvo ao sul, em uma faixa que percorre os bairros Jardim do Rosário e Camargos, onde inexistem estes espaços.

Sobre a concentração de pessoas de 12 a 18 anos (Figura 4), novamente vemos a porção sudoeste se destaca, indicando uma dinâmica demográfica que acentua a necessidade de áreas verdes urbanas, mostrando novamente alto número de pessoas, neste caso, de adolescentes no bairro Novo Tempo I.

A porção central (se assemelhando à representação anterior das crianças), exibe quantidade significativa de adolescentes e que em parte também não é atendida pela abrangência de alguma área verde urbana, sobretudo ao sul, nos bairros Independência e novamente o Santa Maria.

Figura 4 - Número de adolescentes por setor censitário (12 a 18 anos).

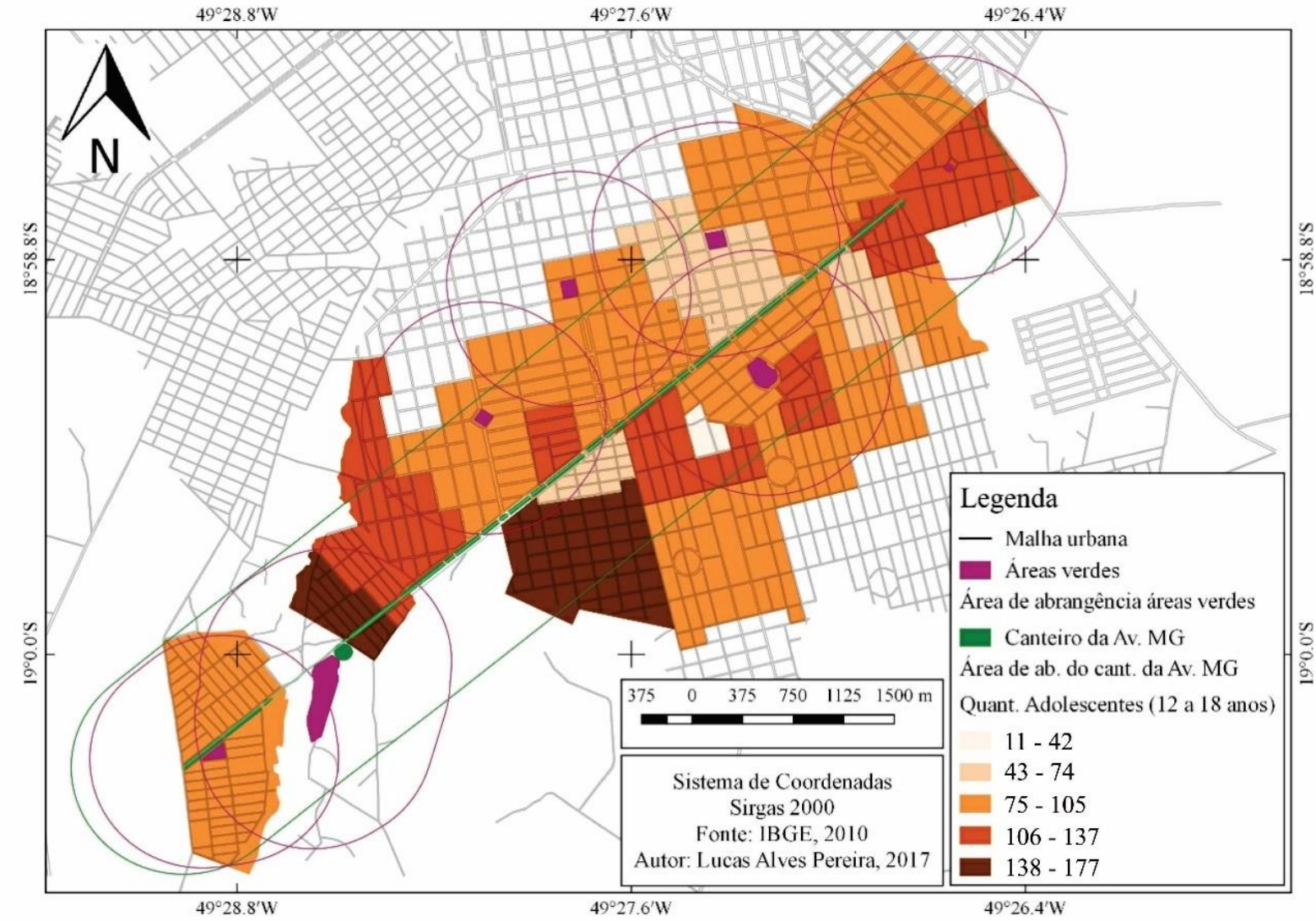

Fonte - IBGE, 2010; Organização: : Lucas Alves Pereira (2017).

A porção nordeste possui relativa concentração de adolescentes, e como dito anteriormente a localização ao sul não dispõe de área verde urbana. No entanto, em ordem de prioridade de intervenção, entendemos que a porção sudoeste carece de mais atenção devido à maior concentração de adolescentes.

Quanto a concentração de pessoas com 60 anos ou mais (Figura 5), a porção sudoeste apresenta número muito baixo de idosos, enquanto a porção central pode ser definida em mista devido a variação de muito concentrada ao norte a levemente concentrada ao sul. Na porção nordeste temos uma concentração de idosos é mediana em relação às demais porções do canteiro da avenida Minas Gerais. 
Figura 5 - Número de idosos por setor censitário (mais de 60 anos).

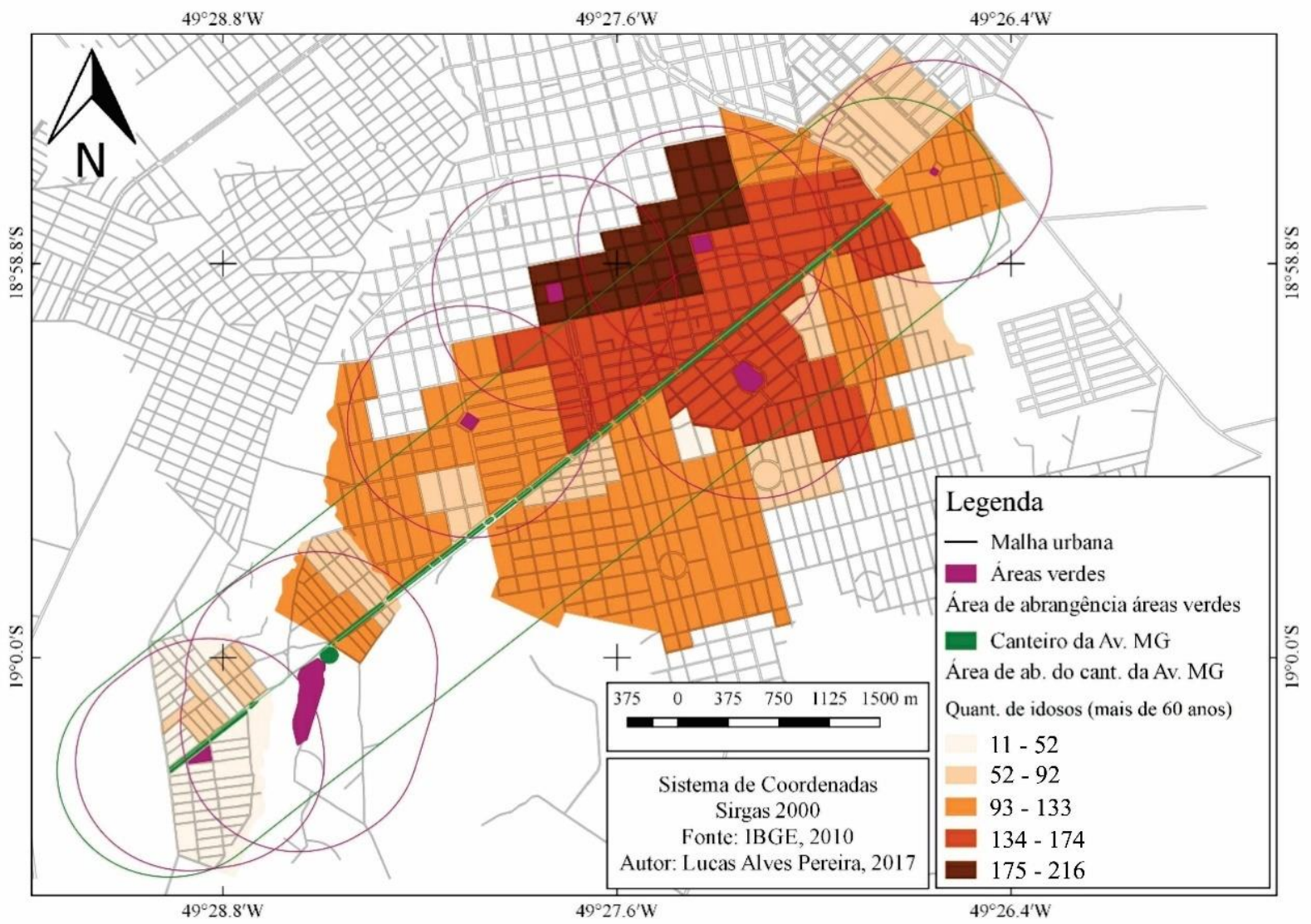

Fonte - IBGE, 2010; Organização: : Lucas Alves Pereira (2017).

Observando a distribuição das faixas etárias ao longo do canteiro notamos a mudança no sentido centro e periferia da cidade. Levando em consideração a área de abrangência estabelecida, uma maior concentração de crianças e adolescentes se apresenta nos bairros localizados na periferia da cidade de Ituiutaba, ou como demonstrado anteriormente, na porção sudoeste da avenida Minas Gerais. De outro modo, a concentração de idosos estão localizados na porção central do canteiro, sobretudo ao sul que é representado pelo centro da cidade.

Provido dos dados obtidos ao longo do presente trabalho, podemos então elaborar uma síntese com o objetivo de orientar intervenções futuras. A síntese pode servir de apoio ao planejamento, que em grande medida não se faz presente na organização e distribuição das áreas verdes.

Ponderando a partir do raio de abrangência, manifestam-se precisamente três pontos específicos (Figura 6), delimitados a partir de áreas não abarcadas e consideradas a quantidade de pessoas de cada faixa etária. Nestes pontos, devido também às condições físicas e estruturais do canteiro, são passíveis de intervenções. 
Figura 6 - Pontos para intervenções no canteiro central da Avenida Minas Gerais.

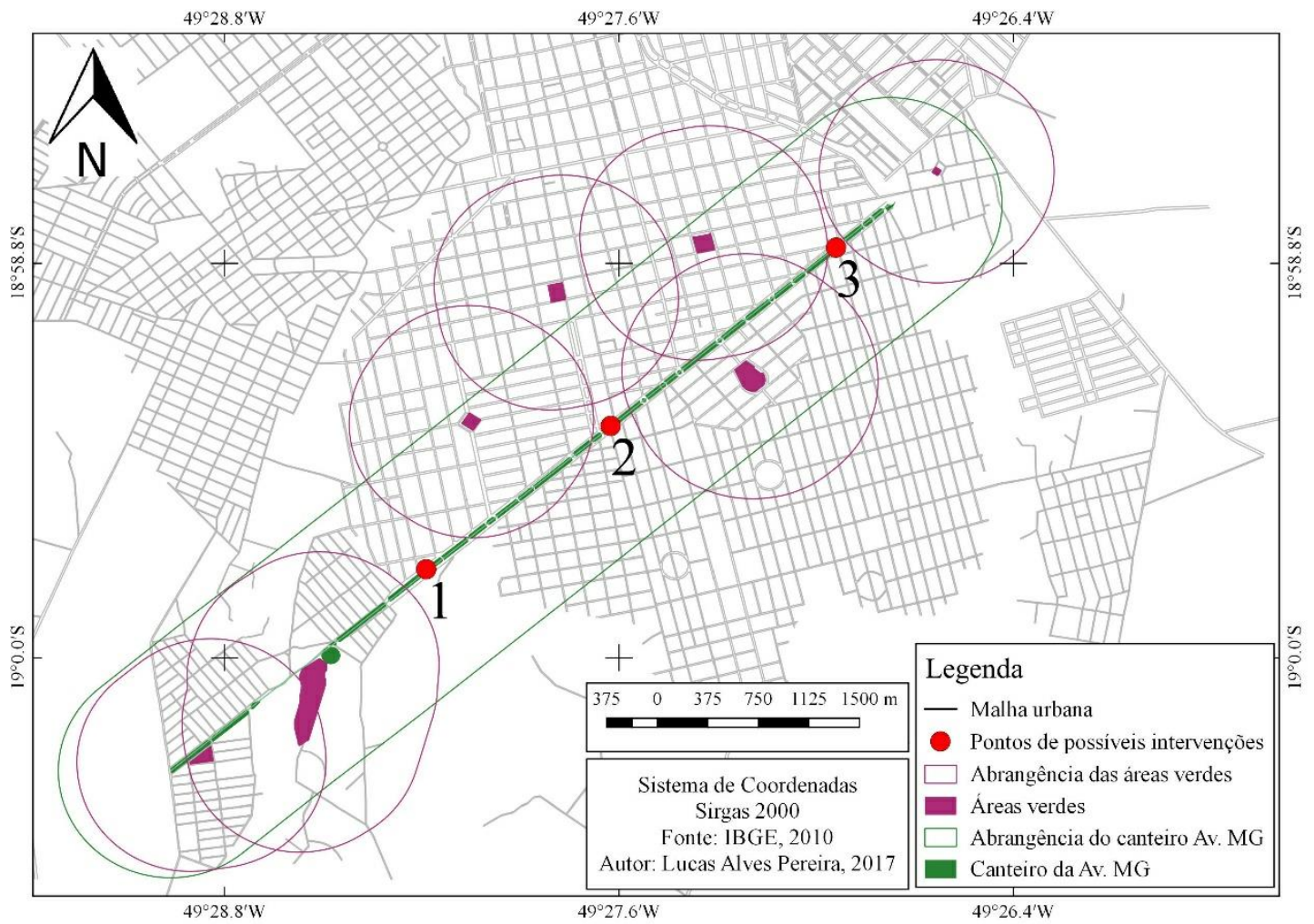

Fonte - IBGE, 2010; Organização: Lucas Alves Pereira (2017).

De acordo com os apontamentos acerca dos dados demográficos do entorno do canteiro, evidenciando sua potencialidade, podemos apontar três localizações possíveis para intervenções, beneficiando de sua posição em relação ao entorno para realizar as funções e proporcionar melhor o uso através de incentivos e instrumentos urbanísticos.

As localizações acabam por atender uma hierarquia. Com grande concentração de crianças e adolescentes no entorno, o ponto 1 indicado no mapa, preencheria uma lacuna onde a abrangência das áreas verdes urbanas não se faz presente e existe um contingente populacional, ainda, consequentemente uma estruturação do canteiro acompanharia usos voltados para as faixas etárias de 0 a 18 anos.

De outra forma, o ponto 2 , devido à concentração de idosos, principalmente na porção norte, seria uma segunda localização para uma possível intervenção. No ponto 2, a estrutura carece possuir equipamentos que sustentem o uso por idosos.

Por fim, no ponto 3, a necessidade é de preencher o vazio da abrangência de Áreas Verdes, neste caso, os pontos anteriores se apresentam mais importantes por conta da relação entre o entorno e as possiblidades de ação, sobretudo do Estado, sendo ele capaz de instituir efetivamente espaços para a sociabilidade e adequados ambientalmente.

\section{CONSIDERAÇÕES FINAIS}

Sabemos também, que os conceitos ligados a espaços livres, espaço público, áreas verdes urbana e índices ambientais urbanos carecem de melhor interpretação prática a partir da teoria, corroboramos então da afirmação apresentada por Souza e Amorim (2015), os quais afirmam que as divergências entre teoria, prática e legislação impactam diretamente na ausência de padrões metodológicos e de classificação por vezes, inviabilizando a materialização de resultados efetivos. 
Entendemos que para uma maior compreensão do espaço urbano é necessário a abordagem de elementos de escalas mais abrangentes, no entanto, a síntese das informações foi realizada baseada no recorte escolhido, tendo em vista a aplicabilidade de metodologias capazes de abarcar o tema selecionado. Portanto, os dados e elementos identificados estão diretamente relacionados com a área de abrangência atribuída à Avenida Minas Gerais.

Ainda que considerando toda a cidade de Ituiutaba, as áreas verdes urbanas pareçam se mostrar bem distribuídas na forma de praças, um olhar mais acurado consegue identificar certas deficiências em abrangências. Na proposta aqui trabalhada pudemos demonstrar que determinados setores, sobretudo os de urbanização posterior a 1990, pouco ou nada de áreas verdes urbanas foram estabelecidas.

Foi possível observar também as diferenças significativas ao logo do canteiro da avenida Minas Gerais. Relacionando-o com as caraterísticas demográficas é possível estabelecer melhor dinâmica na proposição e implementação de equipamentos voltados ao lazer e recreação de acordo com cada faixa etária do entorno, permitindo melhor emprego dos recursos, bem como maior efetivação dos usos do público tendo em vista uma leitura mais precisa da realidade urbana local. Seja criando estruturas e novos usos ou ainda proporcionando melhores condições aos usos já existentes.

Portanto, evidenciamos ao longo desta proposta a posição estratégica do canteiro da Avenida Minas Gerais na malha urbana de Ituiutaba, sendo ela considerada como espaço de integração (função básica das vias urbanas) e área verde urbana com seguimentos que melhor exercem suas funções e outros com menor efetividade. Melhorar qualitativamente seus espaços condiz com os pressupostos sustentáveis, tão almejados desde a Rio 92.

\section{AGRADECIMENTOS}

Agradecimento em especial à FAPEMIG pelo apoio financeiro mediante concessão de bolsa.

\section{REFERÊNCIAS}

BARGOS, Danúbia Caporusso; MATIAS, Lindon Fonseca. Áreas verdes urbanas: um estudo de revisão e proposta conceitual. Revsbau, Piracicaba - SP, v. 6, n. 3, p.172-188, set. 2011. https://doi.org/10.5380/revsbau.v6i3.66481

BRASIL. Constituição (1990). Lei no 8069, de 13 de julho de 1990. Estatuto da Criança e do Adolescente. Brasília, DF, Disponível em: <http://www.planalto.gov.br/ccivil_03/leis/L8069.htm>. Acesso em: 02 dez. 2017.

BRASIL. Constituição (2003). Lei no 10741, de 01 de outubro de 2003. Estatuto do Idoso. Brasília, DF, Disponível em: < http://www.planalto.gov.br/ccivil_03/leis/2003/L10.741.htm>. Acesso em: 02 dez. 2017.

CARLOS, Ana Fani Alessandri. Da "organização" à "produção" do espaço no movimento do pensamento geográfico. In: CARLOS, Ana Fani Alessandri; SOUZA, Marcelo Lopes de; SPOSITO, Maria Encarnação Beltrão (Org.). A produção do espaço urbano: agentes e processos, escalas e desafios. São Paulo: Contexto, 2014. p. 53-74.

CORRÊA, Roberto Lobato. O Espaço Urbano. São Paulo: Ática, 1989.

CORRÊA, Roberto Lobato. Sobre agentes sociais, escala e produção do espaço: Um texto para discussão. In: CARLOS, Ana Fani Alessandri; SOUZA, Marcelo Lopes de; SPOSITO, Maria Encarnação Beltrão (Org.). A produção do espaço urbano: agentes e processos, escalas e desafios. São Paulo: Contexto, 2014. p. 41-52.

CORRÊA, Roberto Lobato. Trajetórias geográficas. 6. ed. Rio de Janeiro: Bertrand Brasil, 2011. 304 p.

LEFEBVRE, Henri. O direito à cidade. 5. ed. São Paulo: Centauro, 2001. 144 p. Tradução: Rubens Eduardo Frias 
LIMA, Ana Maria Liner Pereira et al. Problemas de utilização na conceituação de termos como espaços livres, áreas verdes e correlatos. In: CONGRESSO BRASILEIRO DE ARBORIZAÇÃO URBANA, 2., 1994, São Luís. Anais... . São Luís: CBAU, 1994. p. 539 - 553.

LOBODA, Carlos Roberto; DE ANGELIS, Bruno Luiz Domingos. Áreas verdes públicas urbanas: conceitos, usos e funções. Ambiência, 2005.

MARICATO, Ermínia. A cidade do pensamento único: Desmanchando consensos. Petrópolis: Vozes, 2000. $193 \mathrm{p}$.

NOVAES, Rômulo D.; MIRANDA, Aline S.; DOURADO, Victor Z.. Velocidade usual da marcha em brasileiros de meia idade e idosos. Rev Bras Fisioter, São Carlos, v. 2, n. 15, p.117-122, mar. 2011. https://doi.org/10.1590/S1413-35552011000200006

$\mathrm{NUCCl}$, João Carlos. Qualidade ambiental e adensamento urbano: um estudo de ecologia e planejamento da paisagem aplicado ao distrito de Santa Cecília (MSP). 2. ed. Curitiba: O Autor, 2008. $150 \mathrm{p}$.

OLIVEIRA, Hélio Carlos Miranda de. Expansão urbana e desigualdades socioespaciais: o exemplo de Ituiutaba (mg). In: SEMINÁRIO INTERNACIONAL DA REDE IBEROAMERICANA DE INVESTIGADORES SOBRE GLOBALIZAÇÃO E TERRITÓRIO, 2014, Salvador. Anais... . Salvador: Sei, 2014. Disponível em: <www.rii.sei.ba.gov.br/ANAIS_XIII/gt6/GT6_HELIO.pdf>. Acesso em: 04 mar. 2016

SANTOS, Milton. Manual de Geografia Urbana. 3. ed. São Paulo: Edusp, 2012. 232 p. Tradução: Antônia Dea Erdens e Maria Auxiliadora da Silva.

SANTOS, Milton. A natureza do espaço: Técnica e Tempo, Razão e Emoção. 4. ed. São Paulo: Editora da Universidade de São Paulo, 2014. 384 p. (Coleção Milton Santos).

SERPA, Angelo. O espaço público na cidade contemporânea. 2. ed. São Paulo: Contexto, 2014. $205 \mathrm{p}$.

SOUZA, Mariana Cristina da Cunha; AMORIM, Margarete Cristiane de Costa Trindade. Espaço Urbano: Áreas verdes no debate. In: BEININI, Elisângela Medina (Org.). Espaços livres de uso público. Tupã: ANAP, 2015. Cap. 2. p. 34-52.

VASCONCELOS, Pedro de Almeida. A utilização dos agentes sociais nos estudos de geografia urbana: avanço ou recuo. In: CARLOS, Ana Fani Alessandri; SOUZA, Marcelo Lopes de; SPOSITO, Maria Encarnação Beltrão (Org.). A produção do espaço urbano: agentes e processos, escalas e desafios. São Paulo: Contexto, 2014. p. 75-96.

Recebido em: 10/01/2019

Aceito para publicação em: 30/06/2020 